\title{
Voltage Sag Compensation Using Dynamic Voltage Restorer for DFIG Fed Distribution Network
}

\author{
Kondangi Venkata Ramana \\ Ph.D Scholar, Andhra Pradesh, Visakhapatnam \\ R Srinu naik \\ Assistant Professor, Andhra Pradesh, Visakhapatnam
}

\begin{abstract}
This paper investigates compensation of voltage sag due to faults in distribution system for a doubly fed induction motor(DFIG) configuration using dynamic voltage restorer(DVR). Series compensation of terminal voltage during fault conditions using DVR is carried out by injecting voltage at the point of common coupling to the grid voltage to maintain constant DFIG stator voltage. However, the control of the DVR is crucial in order to improve the FRT capability in the DFIG-based wind turbines.wind turbine is controlled by pitch angle which controls the rotor and stator currents of induction generator under different wind speeds. DVR injects voltage in series using vector control which compensates voltage quality problems. The proposed work is verified using matlab/ Simulink software.
\end{abstract}

Keywords: DFIG,DVR.Voltage sag,FRT

DOI: $10.7176 / \mathrm{ISDE} / 10-2-02$

\section{INTRODUCTION}

Energy is main criteria for human development in any country. Any country that can produce energy in large scale can become a developed country in a short time. Mainly energy sources can be divided into two categories. Renewable energy sources and Non-renewable energy sources. Alternatively energy sources are the energy sources different from those in wide spread use at the moments (which are referred to as conventional). Alternative energy sources include solar, wind, wave, and tidal, hydroelectric and geothermal energy [1]. Although they each have their own drawbacks, none of these energy sources produces significant air pollution, unlike conventional sources. Fossil fuels are (Carbon or Hydrocarbon) the fuels derived from what was living material, and found underground or beneath the sea. The most common forms are coal, oil and natural gas. They take millions of years to form. Their energy is only oxygen in air to form carbon dioxide or carbon monoxide and water. Other elements within the fuels are also released into the air after combining with oxygen causing further pollution with $\mathrm{SO}_{2}$ and nitrogen oxide gasses. In the case of coal, ash particles are also a problem.

Non-renewable energy sources that exist in a limited amount on earth. Thus all available material could eventually be completely used up. Coal, Oil and gas are considered as non-renewable energy sources because the rate of their formation is so slow on human time scales that they are using them without being replaced. Generally wind energy is available in abundance[2]. For conversion of this wind energy into electrical energy and induction generator is coupled with a wind mill offers an ideal solution.

Wind energy is available in abundance in our environment. When compared with the conventional sources of energy, wind energy is clean, efficient, and sustainable form of energy. When the cost of supplying electricity to remote locations is expensive, wind energy provides a cost effective alternative. So to convert this wind energy into electrical energy, an induction generator will offer an ideal solution.

A DVR is used to compensate the supply voltage disturbances such as sag and swell. The DVR is connected between the supply and sensitive loads, so that it can inject a voltage of required magnitude and frequency in the distribution feeder. The DVR is operated such that the load voltage magnitude is regulated to a constant magnitude, while the average real power absorbed/ supplied by it is zero in the steady state. The capacitor supported DVR is widely addressed in the literature [3]. The instantaneous reactive power theory (IRPT) [4], sliding mode controller [5], instantaneous symmetrical components [6] etc., are discussed in the literature for the control of DVR. In this project a new control algorithm is proposed based on the current mode control and proportional-integral (PI) controllers for the control of DVR 


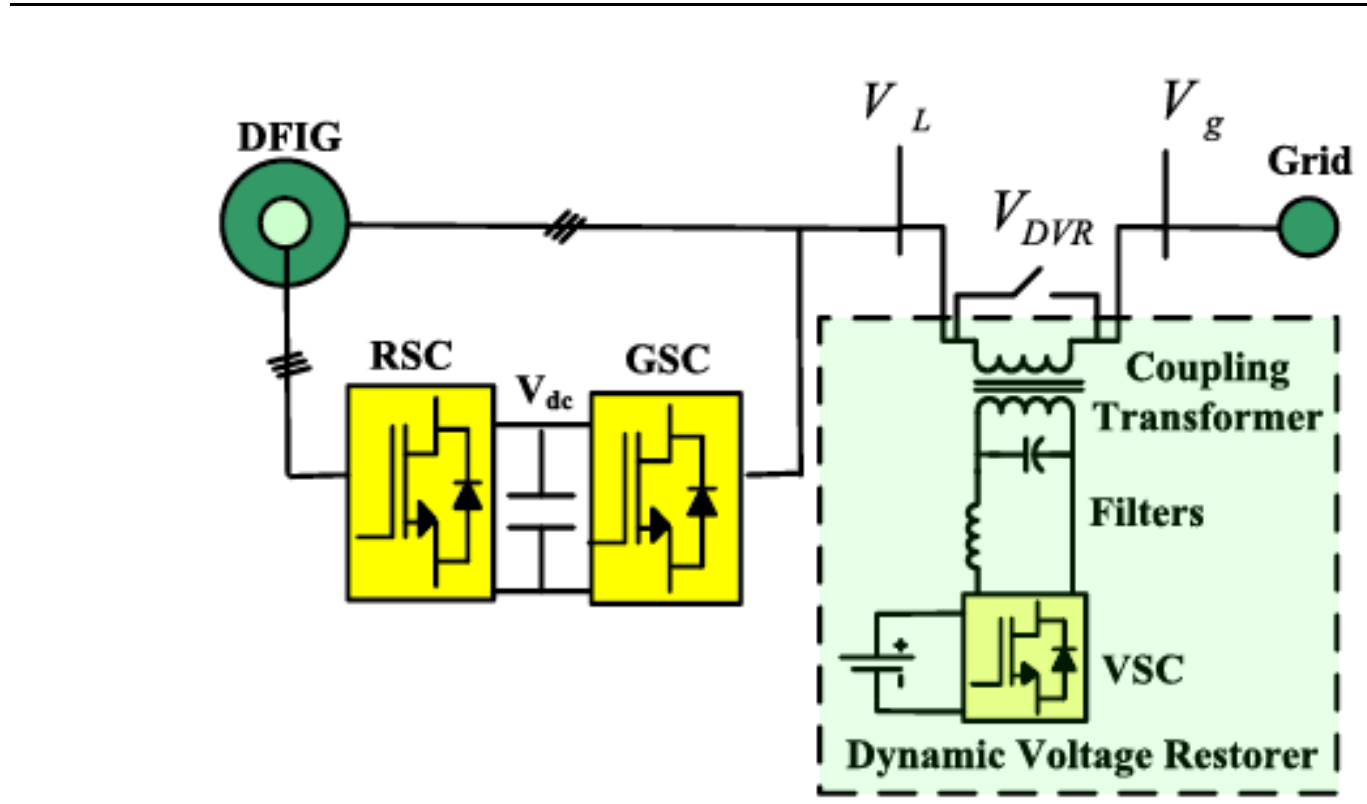

Figure 1. Block diagram of DVR WITH DFIG

\section{DOUBLY FED INDUCTION GENERATOR}

Wind turbines use a doubly-fed induction generator (DFIG) consisting of a wound rotor induction generator and an AC/DC/AC IGBT-based PWM converter. The stator winding is connected directly to the $50 \mathrm{~Hz}$ grid while the rotor is fed at variable frequency through the AC/DC/AC converter. The DFIG technology allows extracting maximum energy from the wind for low wind speeds by optimizing the turbine speed, while minimizing mechanical stresses on the turbine during gusts of wind. The optimum turbine speed producing maximum mechanical energy for a given wind speed is proportional to the wind speed. Another advantage of the DFIG technology is the ability for power electronic converters to generate or absorb reactive power, thus eliminating the need for installing capacitor banks as in the case of squirrel-cage induction generator.

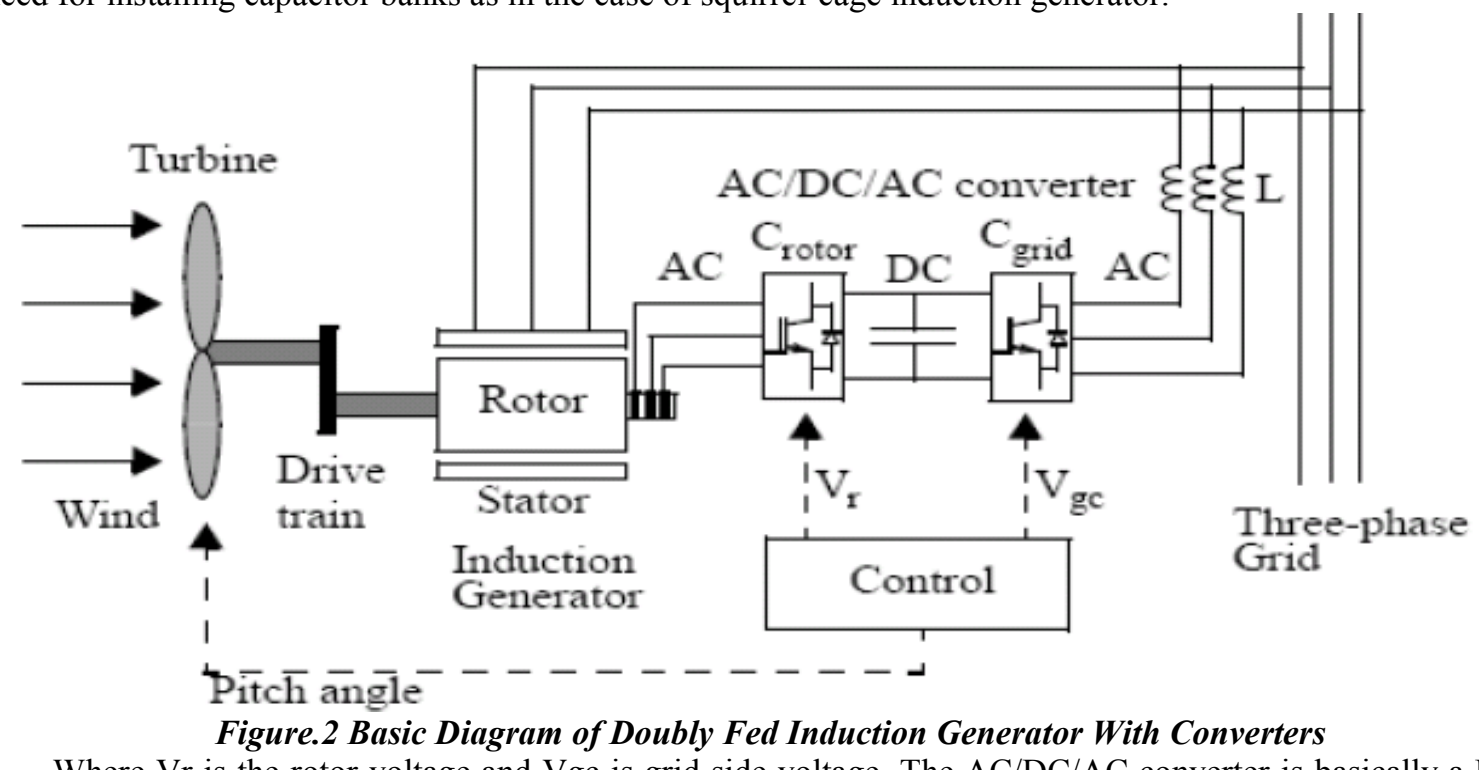

Where $\mathrm{Vr}$ is the rotor voltage and Vgc is grid side voltage. The AC/DC/AC converter is basically a PWM converter which uses sinusoidal PWM technique to reduce the harmonics present in the wind turbine driven DFIG system. Here Crotor is rotor side converter and Cgrid is grid side converter. To control the speed of wind turbine gear boxes or electronic control can be used.

\section{DYNAMIC VOLTAGE RESTORER}

Among the power quality problems (sags, swells, harmonics...) voltage sags are the most severe disturbances. In order to overcome these problems the concept of custom power devices is introduced recently. One of those devices is the Dynamic Voltage Restorer (DVR), which is the most efficient and effective modern custom power device used in power distribution networks. DVR is a recently proposed series connected solid state device that 
injects voltage into the system in order to regulate the load side voltage. It is normally installed in a distribution system between the supply and the critical load feeder at the point of common coupling (PCC). Other than voltage sags and swells compensation, DVR can also added other features like: line voltage harmonics compensation, reduction of transients in voltage and fault current limitations.

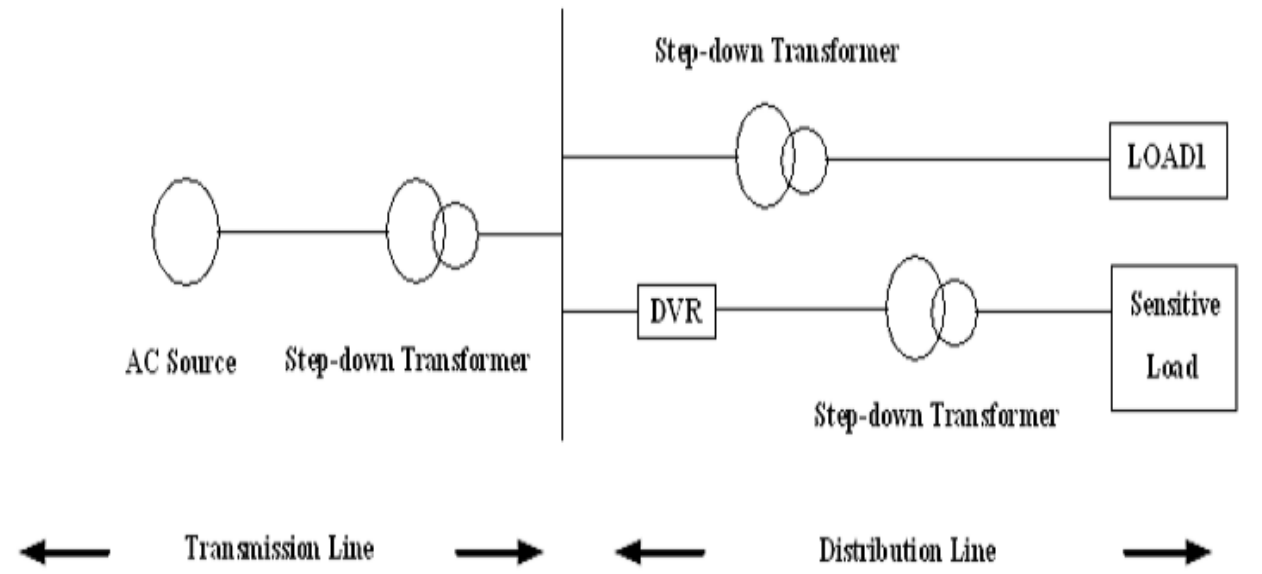

Figure 3. DVR configuration

\section{DVR CONTROL STRATEGY}

The proposed algorithm is based on the estimation of reference supply currents. It is similar to the algorithm for the control of a shunt compensator like DSTATCOM for the terminal voltage regulation of linear and nonlinear loads [6]. The proposed control algorithm for the control of DVR is depicted in Fig 4

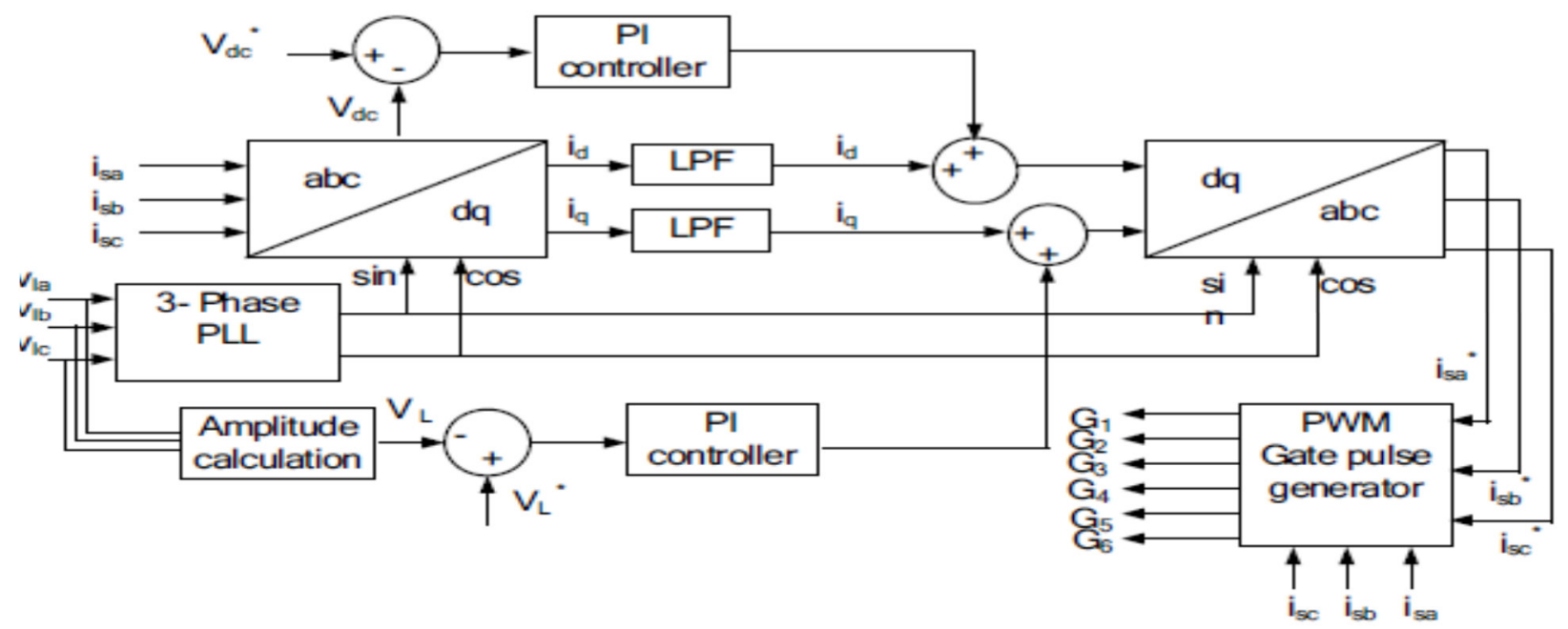

Figure 4 Control scheme of the DVR

The series compensator known as DVR is used to inject a voltage in series with the terminal voltage. The sag and swell in terminal voltages are compensated by controlling the DVR and the proposed algorithm inherently provides a self-supporting dc bus for the DVR. Three-phase reference supply currents (isa*, isb*,isc*) are derived using the sensed load voltages (vla, vlb, vlc), terminal voltages (vta, vtb, vtc) and dc bus voltage (vdc) of the DVR as feedback signals. The synchronous reference frame theory based method is used to obtain the direct axis (id) and quadrature axis (iq) components of the load current. The load currents in the three-phases are converted into the d-q-0 frame using the Park's transformation as, 


$$
\left[\begin{array}{l}
i_{d} \\
i_{q} \\
i_{0}
\end{array}\right]=\frac{2}{3}\left[\begin{array}{ccc}
\cos \theta & -\sin \theta & \frac{1}{2} \\
\cos \left(\theta-\frac{2 \pi}{3}\right) & -\sin \left(\theta-\frac{2 \pi}{3}\right) & \frac{1}{2} \\
\cos \left(\theta+\frac{2 \pi}{3}\right) & \sin \left(\theta+\frac{2 \pi}{3}\right) & \frac{1}{2}
\end{array}\right]\left[\begin{array}{l}
i_{l a} \\
i_{l b} \\
i_{l c}
\end{array}\right]
$$

A three-phase PLL (phase locked loop) is used to synchronies these signals with the terminal voltages (vta, $\mathrm{vtb}, \mathrm{vtc})$. The d-q components are then passed through low pass filters to extract the dc components of id and iq. The error between the reference dc capacitor voltage and the sensed dc bus voltage of DVR is given to a PI (proportional-integral) controller of which output is considered as the loss component of current and is added to the dc component of id. Similarly, a second PI controller is used to regulate the amplitude of the load voltage (Vt). The amplitude of the load terminal voltage is employed over the reference amplitude and the output of PI controller added with the dc component of iq. The resultant currents are again converted into the reference supply currents using the reverse Park's transformation. Reference supply currents (isa*, isb*,isc*) and the sensed supply currents (isa, isb, isc) are used in PWM current Controller to generate gating pulses for the switches. The PWM controller operates at a frequency of $10 \mathrm{kHz}$ and the gating signals are given to the three-leg VSC for the control of supply currents.

\section{SIMULINK IMPLEMENTATION OF DFIG}

Simulink is a software package for modeling, simulating, and analyzing dynamical systems. It supports linear and nonlinear systems, modeled in continuous time, sampled time, or a hybrid of the two. Systems can also be multirate, i.e., have different parts that are sampled or updated at different rates. For modeling, Simulink provides a graphical user interface (GUI) for building models as block diagrams, using click-and-drag mouse operations. With this interface, you can draw the models just as you would with pencil and paper (or as most textbooks depict them). This is a far cry from previous simulation packages that require you to formulate differential equations and difference equations in a language or program. Simulink includes a comprehensive block library of sinks, sources, linear and nonlinear components, and connectors. You can also customize and create your own blocks. For information on creating your own blocks, see the separate Writing S-Functions guide.

\section{Wind Turbine:}

The model is based on the steady-state power characteristics of the turbine. The stiffness of the drive train is infinite and the friction factor and the inertia of the turbine must be combined with those of the generator coupled to the turbine. The output power of the turbine is given by the following equation.

$$
P_{m}=c_{p}(\lambda, \beta) \frac{\rho A}{2} v_{\text {wind }}^{3}
$$

where $\mathrm{Pm}=$ Mechanical output power of the turbine $(\mathrm{W})$

$\mathrm{Cp}=$ Performance coefficient of the turbine

$\bar{p}=$ Air density $(\mathrm{kg} / \mathrm{m} 3)$

$\mathrm{A}=$ Turbine swept area $(\mathrm{m} 2)$

Vwind $=$ Wind speed $(\mathrm{m} / \mathrm{s})$

$=$ Tip speed ratio of the rotor blade tip speed to wind speed

$\beta=$ Blade pitch angle $(\mathrm{deg})$

Equation 5.1 can be normalized in the per unit (pu) system we have:

$$
P_{m \_ \text {pu }}=k_{p} c_{p_{-} \mathrm{pu}} v_{\text {wind_pu }}^{3}
$$

The Simulink model of the turbine is illustrated in the following figure. The three inputs are the generator speed (wr_pu) in pu of the nominal speed of the generator, the pitch angle in degrees and the wind speed in $\mathrm{m} / \mathrm{s}$. The tip speed ratio in pu of $\mathrm{p} \_$nom is obtained by the division of the rational speed in pu of the base rotational speed (defined below) and the wind speed in pu of the base wind speed. The output is the torque applied to the generator shaft. 


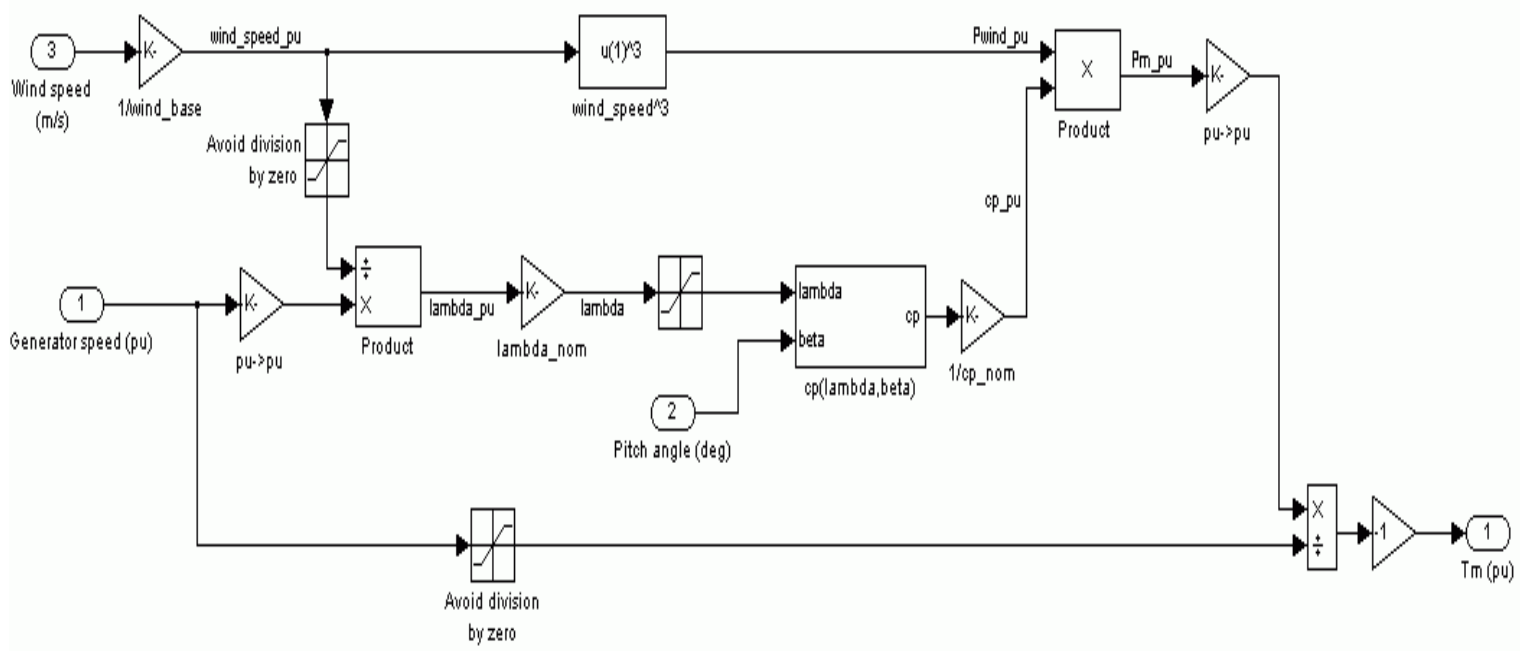

Figure.5 Simulink Implementation of Wind Turbine

\section{Active and Reactive power controllers:}

There are two ways to control the reactive power in a doubly fed induction generator. The grid side converter can work as a static VAR compensator (STATCOM) and the rotor side converter can control the reactive power at the stator through the $\mathrm{Vrq}$ axis voltage. Normally the q-axis rotor voltage will regulate the reactive power to minimum power loss in the wound machine. Then only the grid side converter will control the reactive power from the wind turbine.

\section{DFIG Open model:}

In the open model doubly fed induction generator is runned at a specified speed with the stator disconnected from the grid ( $\mathrm{Is}=0$ ). The rotor is suddenly excited with the slip frequency voltages derived from voltage regulator so as to produce commanded open circuit stator terminal voltage. The specified operating conditions and final values of the variables reached in the steady state are all saved in the workspace to serve as initial conditions in a subsequent simulation.

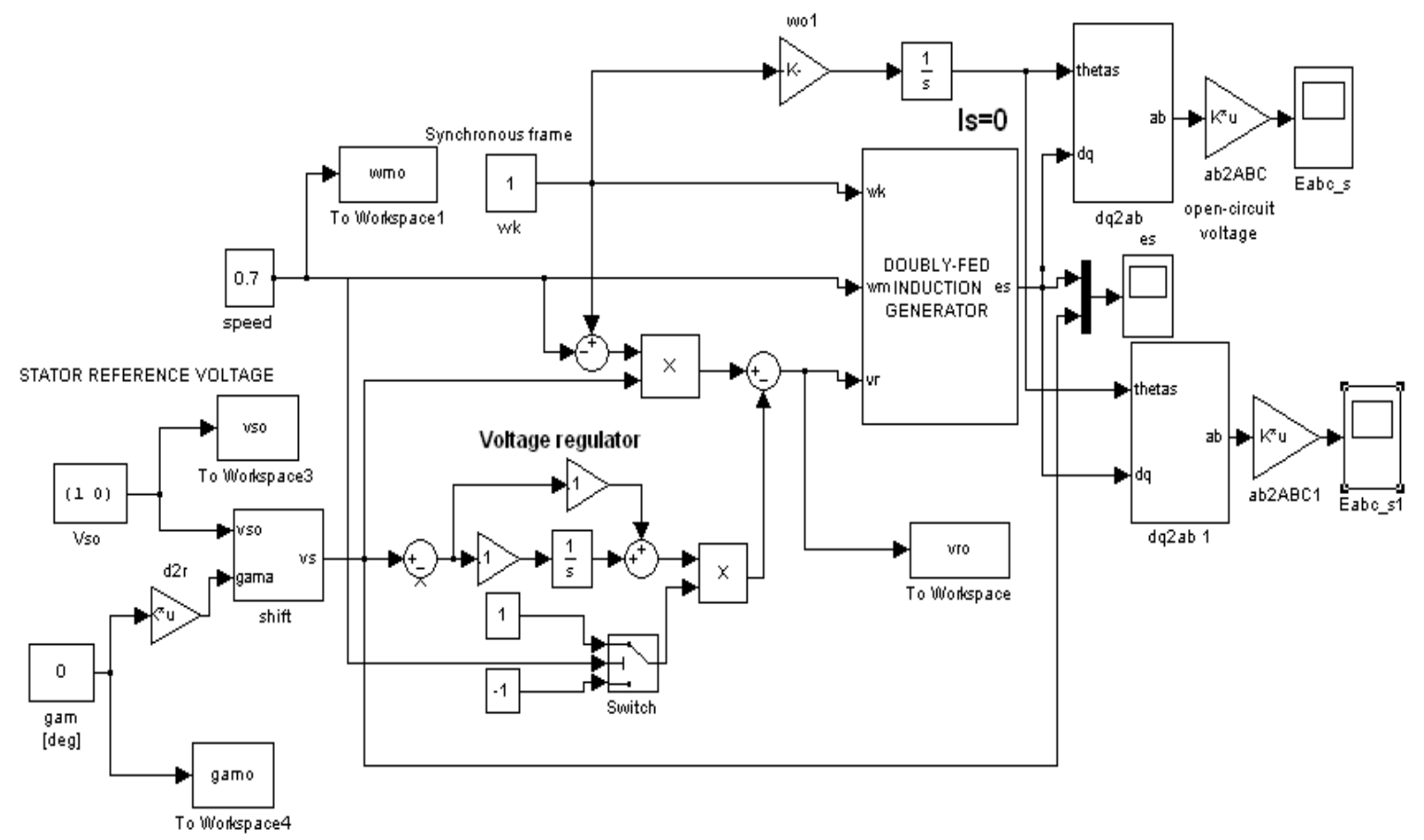

Figure.6 DFIG Open Model (Stator Open Circuited Is=0)

DFIG connected model:

The doubly fed induction machine is modeled in vectorized form in the synchronous frame associated with the 
stator voltage space vector. The d-q components of the injected rotor voltage $\mathrm{Vr}$, at slip frequency $\omega_{\mathrm{r}}$ are derived from PI controllers. $V_{r d}$ is the output of the cascade arrangement of speed and Ps controllers. $V_{\text {rq }}$ is derived from a Qs controller. The mechanical system is modeled as two inertias coupled by means of flexible shaft. The whole system is described by parameters expressed in p.u. The machine representations are based on the motor convention. Consequently in the generator mode of operation, such quantities as Ps, Qs, Tw, Te are negative (with $\left.\omega_{\mathrm{m}}>0\right)$ while $\operatorname{Pr}$ is positive for sub-synchronous operation and negative for super-synchronous mode of operation.

The inputs are $\omega_{\mathrm{k}}$ (Speed of reference frame in p.u), $\omega_{\mathrm{m}}$ (Generated speed), Vs (Stator dq voltage), Vr (Controlled rotor dq voltage). It is modeled in flux linkages. The outputs are Te (electromagnetic torque), is (Stator dq current), ir (Rotor dq current).

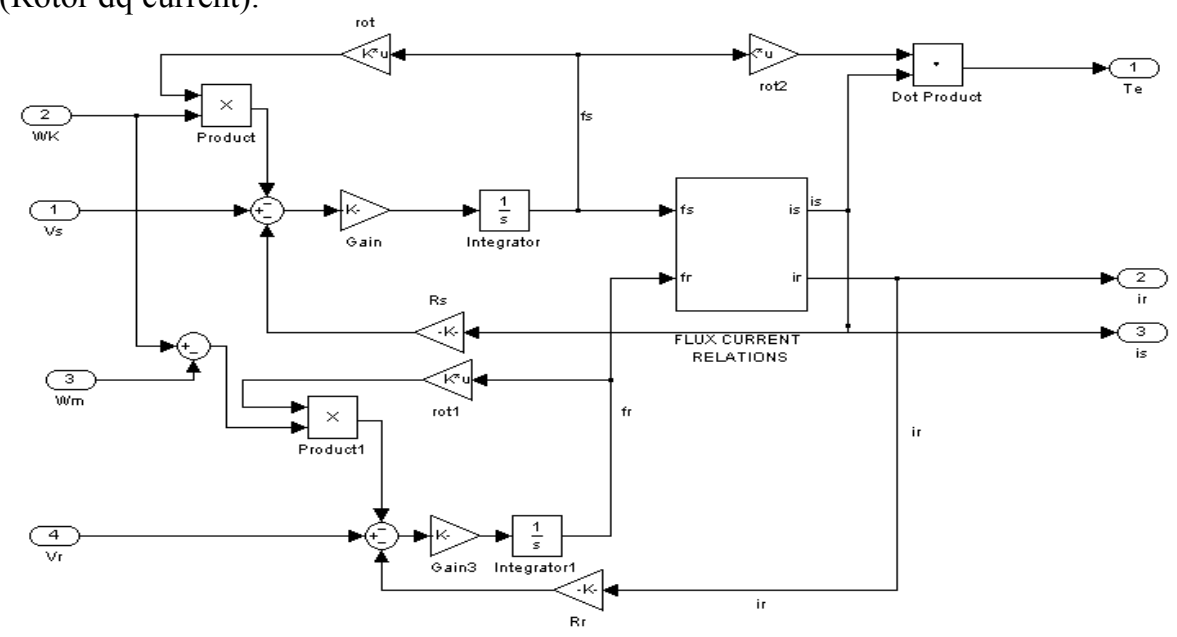

Figure .7 Dynamic Model of Induction Machine in Arbitrary Reference Frame

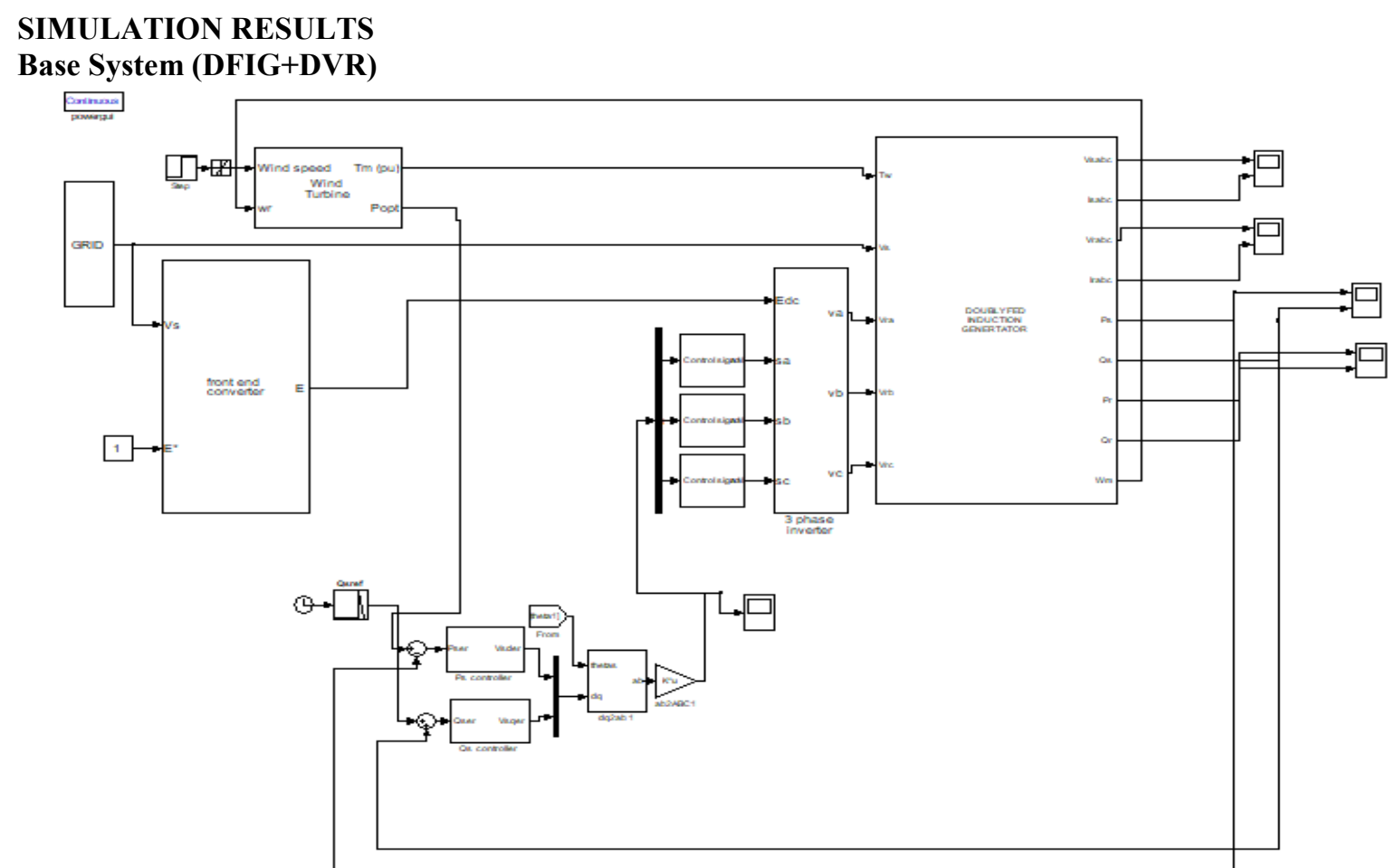

Figure 8.DFIG MODEL 


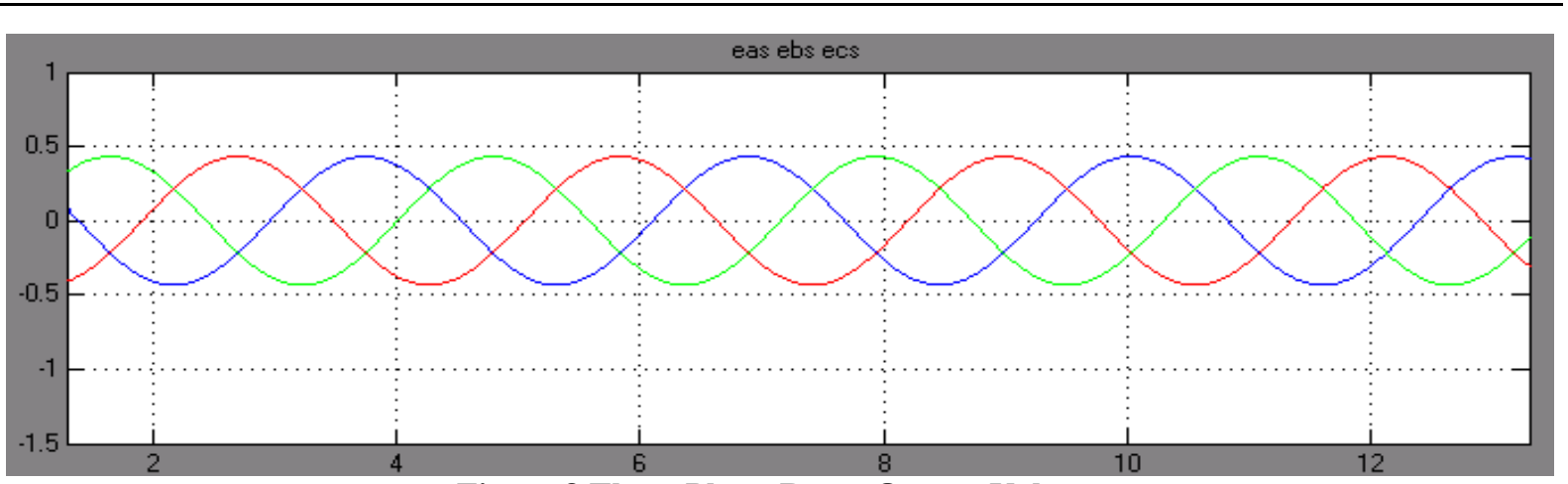

Figure 8.Three Phase Rotor Output Voltage

This is the block diagram showing source, load and transmission line in faulty conditions. The fault can be of any nature like L-G, L-L-G, L-L or 3-PHASE FAULT. In these conditions severe fault currents flow through the lines and there is a drastic drop in line and load voltages.

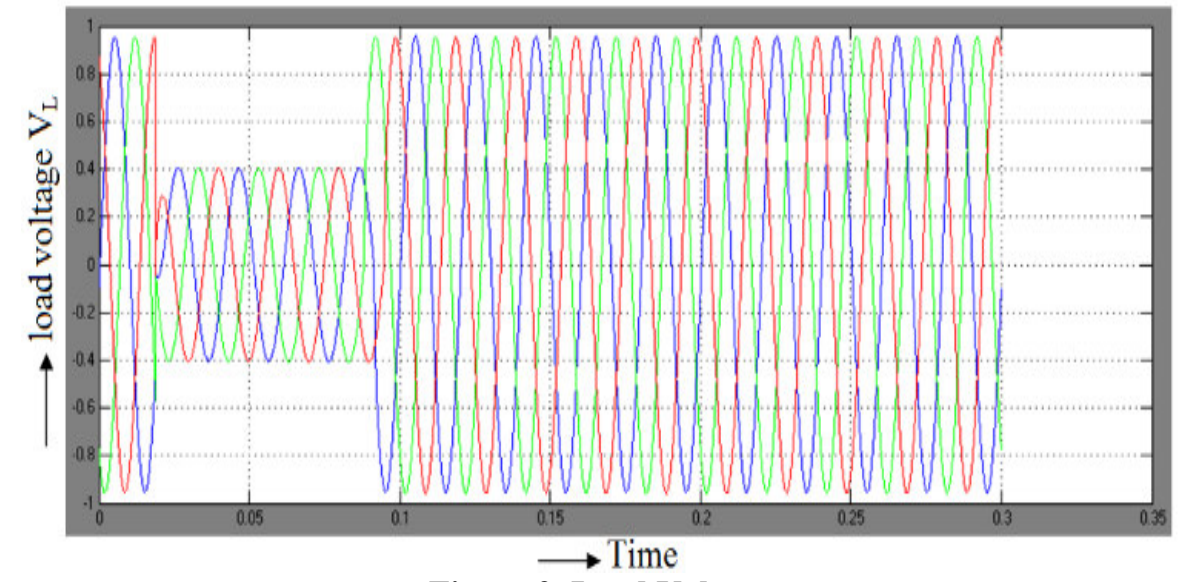

Figure 9. Load Voltage

The drop in the load voltage can be seen in above wave form due to fault in transmission line.

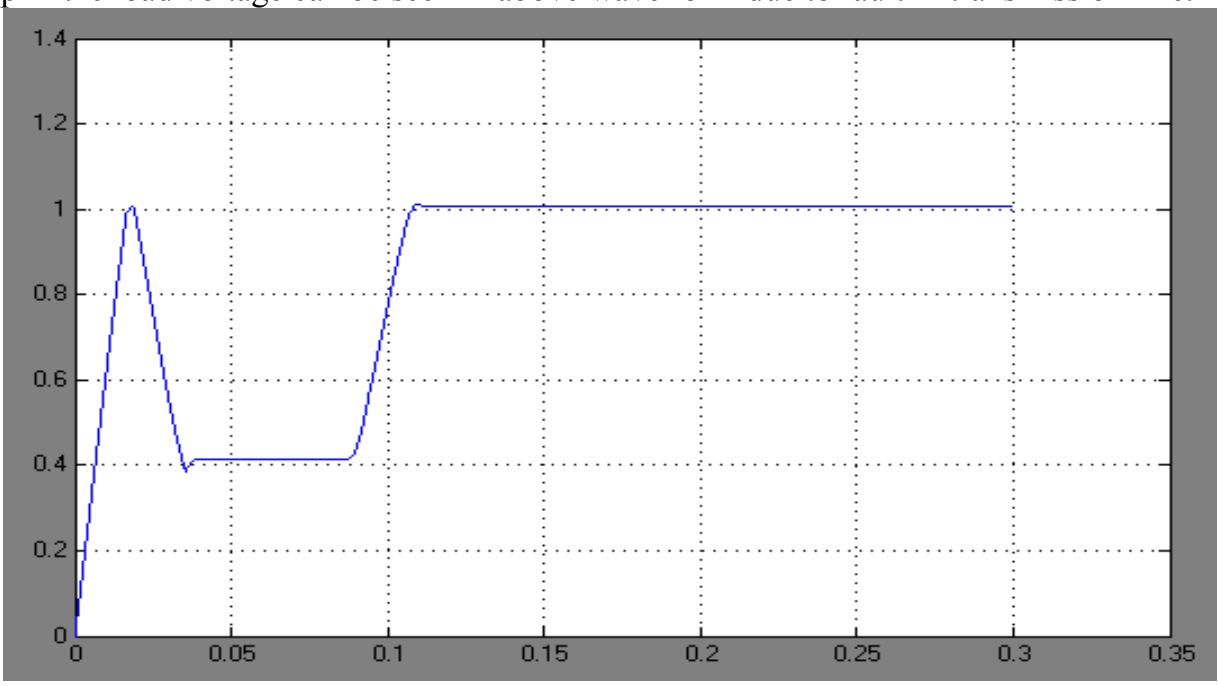

Figure 10. Voltage Sag

The sag in the voltage waveform which can be clearly observed in the above figure which is deviating from the actual voltage curve. 


\section{Base System with PI Controller}

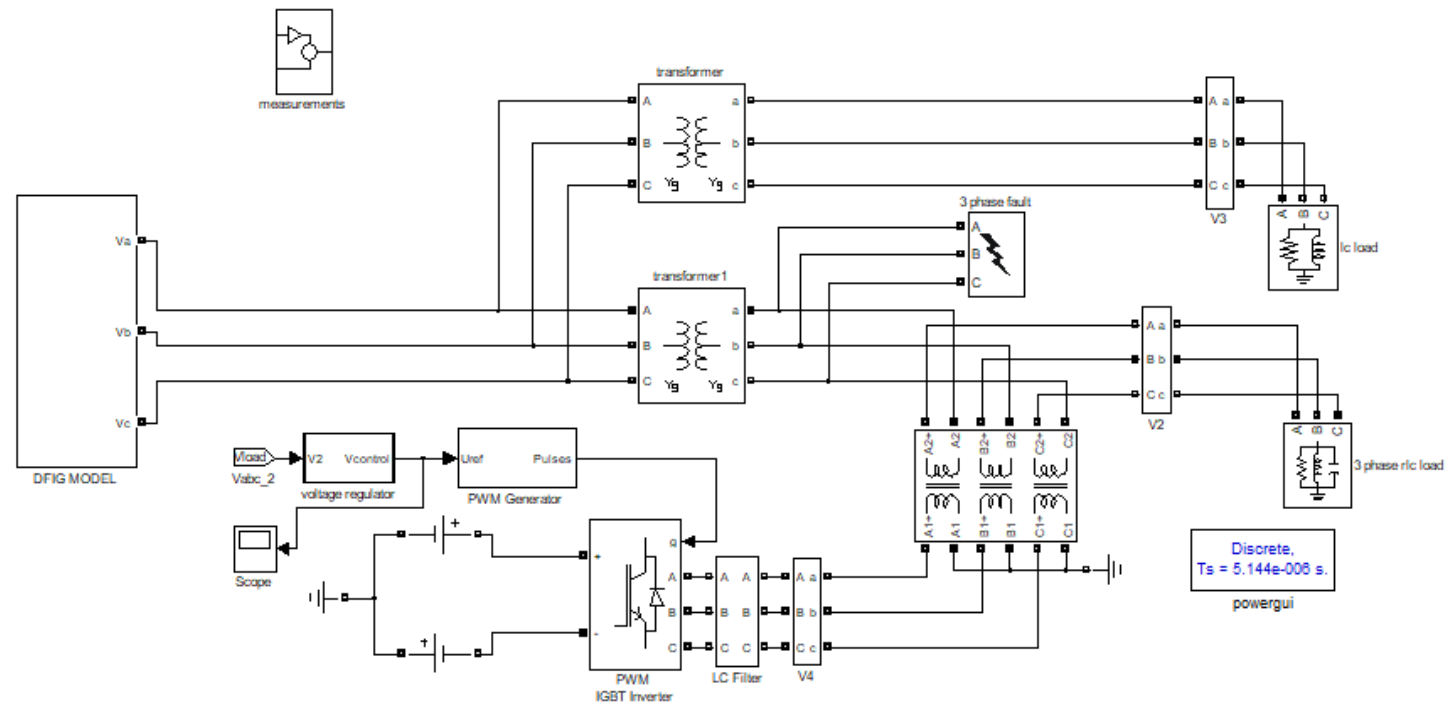

Figure 11. DFIG+DVR with PI Controller

This is the block diagram showing source, load and transmission line in faulty conditions. The type and intensity of fault can be identified and corrected with the DVR and its control mechanism. And bring back the voltage levels to the normal operating value before the occurrence of fault.

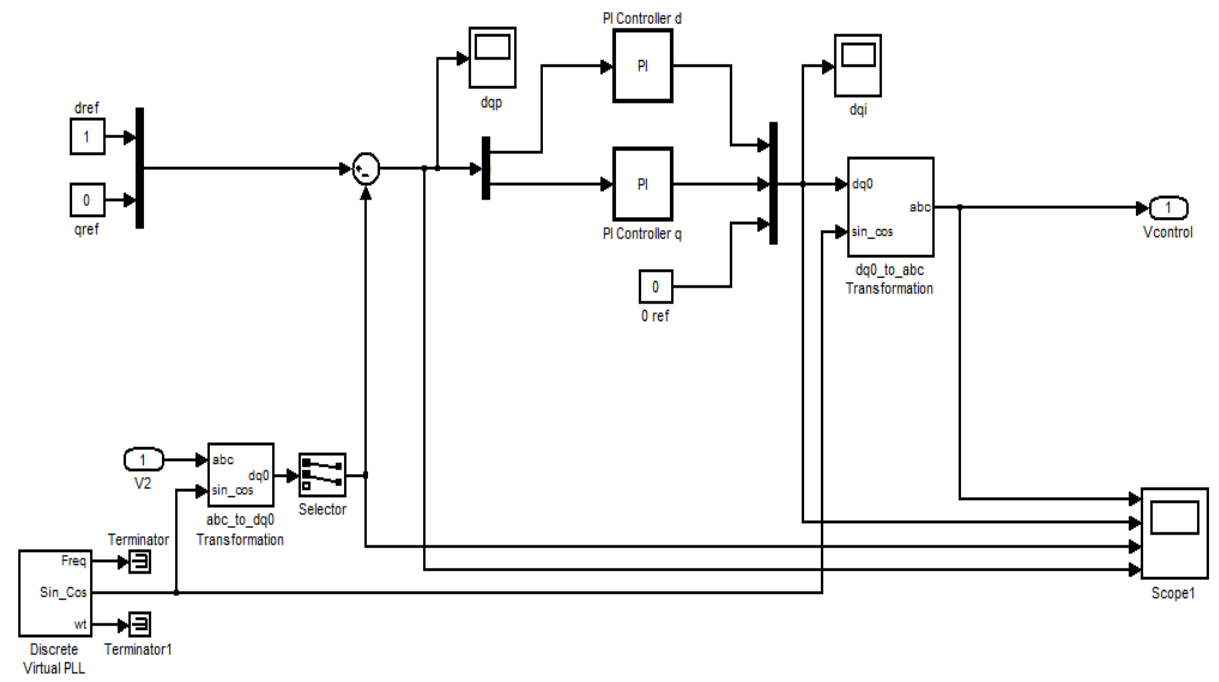

The controller used in the above simulation circuitry is pi controller. Since pi being a conventional controller there is a difficulty in tuning the controller 


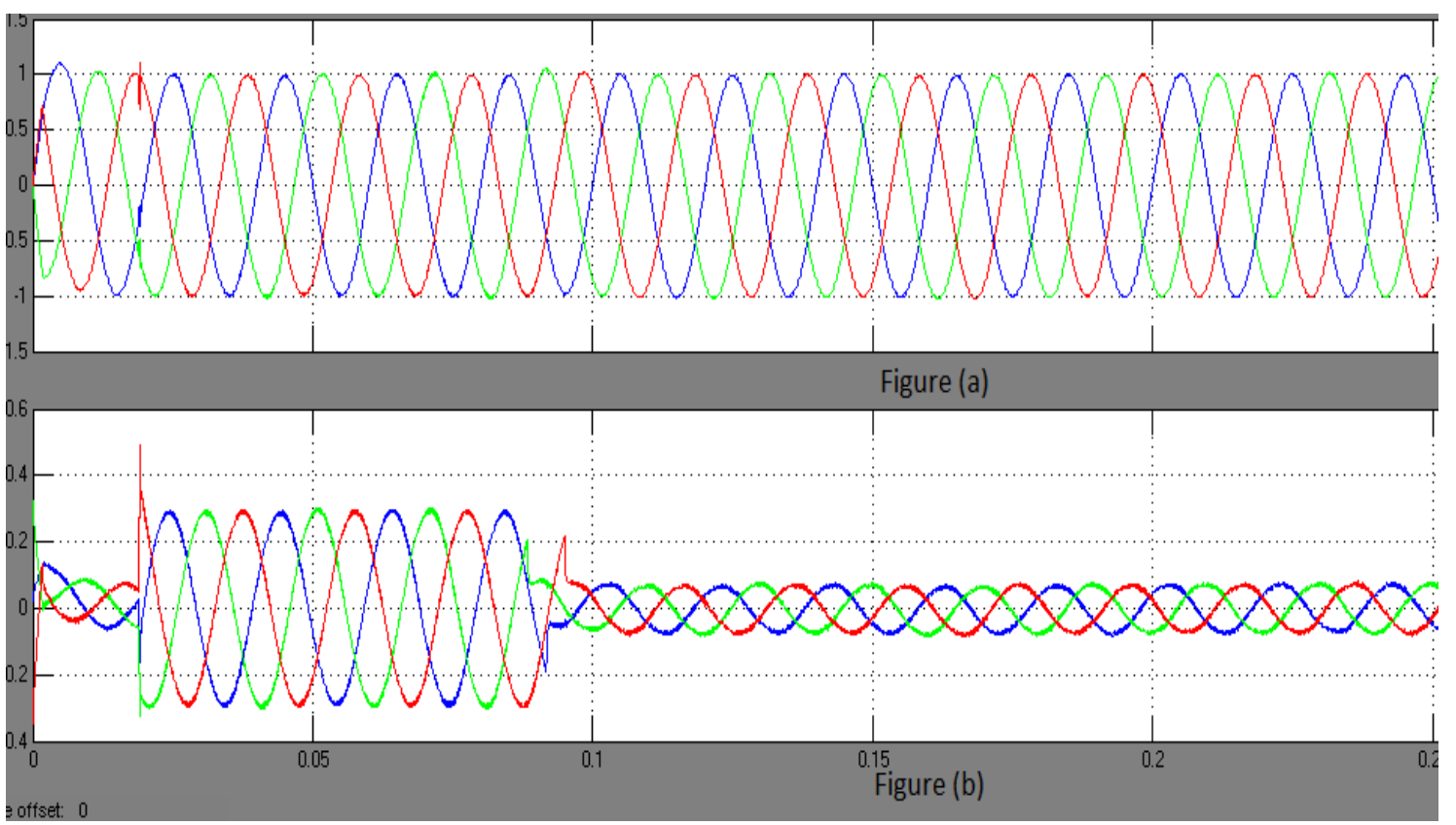

Figure 12. Injected voltage by the DVR

In the above figure the first waveform implies the compensated load voltage at the consumer side. The second waveform implies the injected voltage by the DVR into the lines to compensate the voltage drop.

\section{CONCLUSION}

This paper investigates the performance of DVR with DFIG for voltage sag compensation and to maintain synchronization under wind variations. Dq transformation with PI controller is better results under fault conditions. The rotor voltage and current can be controlled using pitch angel control at wind turbine. The DVR proves to deliver very good transient voltage control, fault current control and reactive power support. The controller contributes in better harmonic compensation compared to conventional control.

\section{References}

1) A.Dendouga, R. Abdessemed, M. L. Bendaas and A. Chaiba LEB-Research Laboratory, Department of Electrical engineering, Batna University, Algeria "Decoupled Active and Reactive Power Control of a Doubly-Fed Induction Generator (DFIG)", proceedings of the $15^{\text {th }}$ Mediterranean conference on control \& Automation, July 27-29,2007, Athens,-Greece.

2) B.Chitti Babu, K.B.Mohanty, "Control of Double-Output Induction Machine for Variable Speed Wind Energy Conversion System Using Dynamic Vector Approach".

3) Chitti Babu B, K.B.Mohanty, C. Poongothai, "Steady State Analysis and Control of Wind Turbine Driven Double-Output Induction Generator", 2009 3rd International Conference on Power Electronics Systems and Applications.

4) S. K Salman and Babak Badrzadeh School of Engineering, The Robert Gordon University, IEEE paper on, "New Approach for modeling of Doubly-Fed Induction Generator (DFIG) for grid-connection studies".

5) S. Muller, M. Deicke and R.W. De Doncker, "Doubly fed induction generator systems for wind turbine", IEEE Industry Applications Magazine, Vol.8, No. 3, pp. 26-33, 2002.

6) Peterson A. Analysis, "Modeling and control of Doubly-Fed Induction Generators for wind turbines". Licentiate thesis; Chalmers University, Gutenberg, Sweden, 2003.

7) Ong CM. "Dynamic Simulation of electric machinery using MATLAB/SIMULINK"; Prentice Hall, 1998.

8) Branislav Dosijanoski, M.Sc. Student, Faculty of Electrical Engineering and Information Technologies, University, "Simulation of Doubly-Fed Induction Generator in a Wind Turbine", XI International PhD Workshop OWD 2009, 17-20 October 2009.

9) Hengameh Kojooyan Jafari "Simulation of Doubly-fed Machine with Improved Wind turbine" Wseas transactions on circuits and systems.

10) Peresada, S., Tilli, A., Tonielli, A, "Robust active-reactive power control of a doubly fed induction machine". IEEE Proc, Sept 1998, pp.1621-1625. 